TEIXEIRA, U.H.G. et al. Co-produtos agroindustriais para suplementos. PUBVET, Londrina, V. 8, N. 14, Ed. 263, Art. 1749, Julho, 2014.

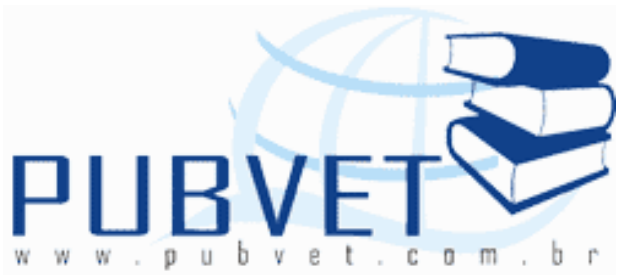

PUBVET, Publicações em Medicina Veterinária e Zootecnia.

\title{
Co-produtos agroindustriais para suplementos
}

1 Mestrandos em Zootecnia, PPGZ/UFMT/ICAA - Sinop, Mato Grosso, Brasil

${ }^{2}$ Mestrandos em Ciência Animal, PPGCA/UFMT/FAMEVZ - Cuiabá, Mato Grosso, Brasil.*E-mail: simioni@zootecnista.com.br

\section{Resumo}

No sistema de criação a pasto ainda predominante no Brasil o período seco apresenta baixo potencial de ganho de peso devido à escassez de chuvas que comprometem a qualidade e quantidade forrageira limitando a produção. A utilização de co-produtos pode levar o barateamento do custo de produção de ruminantes, principalmente na utilização de suplementos fornecido no período seco do ano. Co-produto pode ser obtido através do processamento de frutas de indústrias de suco e da indústria do biodiesel que utiliza culturas oleaginosas para a extração do óleo. Pesquisas recentes vêm apresentando resultados que mostram um melhor desempenho quando se trabalha com estratégias de manejo do pastejo e também de suplementação concentrada na produção de bovinos de corte a pasto.

Palavras-chave: bovinos de corte, desempenho, nutrição animal. 
TEIXEIRA, U.H.G. et al. Co-produtos agroindustriais para suplementos. PUBVET, Londrina, V. 8, N. 14, Ed. 263, Art. 1749, Julho, 2014.

\section{Agroindustrial co-product for supplements}

\section{Abstract}

In creating a pasture system still prevalent in Brazil during the dry season has low potential for weight gain due to lack of rainfall which affect the quality and quantity forage limiting. The use of co-products can take the cheaper the cost of producing ruminants, especially the use of supplements provided in the dry season. Co-product can be obtained by processing fruit juice industries and the biodiesel industry that uses oilseed crops for oil extraction. Recent research has shown one results show a better performance when working with grazing management strategies and also concentrate supplementation on the production of beef cattle on pasture.

Keywords: beef cattle performance, animal nutrition.

\section{INTRODUÇÃO}

No sistema de criação a pasto ainda predominante no Brasil o período seco apresenta baixo potencial de ganho de peso devido à escassez de chuvas que comprometem a qualidade e quantidade forrageira limitando a produção (Reis et al., 2009). Uma estratégia usada para corrigir o problema é a suplementação visando corrigir as deficiências forrageiras utilizando cereais que, no entanto oneram o custo de produção visto que a alimentação pode representar até $70 \%$ dos custos da atividade.

O modelo de produção da pecuária nas últimas décadas mudou sensivelmente, e passou a priorizar tecnologias mais intensivas de capital, que geraram significativos ganhos na produtividade da terra e, conseqüentemente um expressivo efeito "poupa terra", além de avanços na qualidade do produto (Zervoudakis et al., 2011).

A utilização de co-produtos pode levar o barateamento do custo de produção de ruminantes, co-produto pode ser obtido através do processamento de frutas de indústrias de suco (Rogério et. al., 2009) e da 
TEIXEIRA, U.H.G. et al. Co-produtos agroindustriais para suplementos. PUBVET, Londrina, V. 8, N. 14, Ed. 263, Art. 1749, Julho, 2014.

indústria do biodiesel que utiliza culturas oleaginosas para a extração do óleo (Abdalla et al., 2008).

Com o crescimento de $85,5 \%$ na produtividade agrícola nos últimos quatorzes anos, o agronegócio brasileiro vem crescendo, e atualmente representa, aproximadamente, 33\% do Produto Interno Bruto (PIB) e 37\% dos empregos gerados no Brasil (IBGE, 2008). Apesar do crescimento do agronegócio e sua importância para economia do Brasil, existe uma preocupação com a quantidade e a diversidade de co-produtos agroindustriais conseqüente da colheita e do processamento dos produtos agrícolas, respectivamente.

Afonso Neto (1984) estimou que pelo menos 130 milhões de toneladas de co-produtos eram produzidas anualmente pelas diferentes atividades agrícolas. A América Latina produz mais de 500 milhões de toneladas de co-produtos, sendo o Brasil responsável por mais da metade desta produção (Souza \& Santos, 2002). Nesse contexto a categoria de co-produtos, abriu-se um novo seguimento na produção e que está voltado para a avaliação desses alimentos economicamente interessantes e tecnicamente viáveis, tornando-se necessário o conhecimento de sua composição bromatológica, potenciais e limites de sua utilização para maximização do desempenho animal (Galati, 2011).

Os animais ruminantes com expressiva atividade fermentativa prégástrica possuem um grande potencial para utilização, de forma eficiente, de co-produtos agroindustriais, uma vez que, os mesmo são capazes converter alimentos com elevados teores de fibra (celulose, hemicelulose e pectina) em produtos de excelente qualidade para o consumo humano, como leite, carne e seus derivados (Valadares Filho \& Pina, 2006). Esse potencial de utilização de co-produtos agroindustriais, por parte, dos animais ruminantes, já é uma característica ambiental e economicamente importante para a região a medida que diminui o impacto ambiental, o qual pode ser causado pelo armazenamento desses co-produtos em locais inadequados, representado um sério problema de contaminação ambiental, principalmente dos recursos hídricos e do solo (Pereira et al. 2000). 
TEIXEIRA, U.H.G. et al. Co-produtos agroindustriais para suplementos. PUBVET, Londrina, V. 8, N. 14, Ed. 263, Art. 1749, Julho, 2014.

\section{REVISÃO DE LITERATURA}

A bovinocultura de corte no Brasil evoluiu com a expansão da fronteira agropecuária e um grande aumento do rebanho, porém nos dias atuais surgem iniciativas que visam melhorar a capacidade produtiva dos sistemas e da unidade de produção, baseada em modelos produtivos compatíveis com a realidade do local ou da região. Esse sistema encontra-se em constante evolução (Paixão et al., 2006).

Atualmente, a suplementação alimentar dos rebanhos bovinos se encontra em amplo crescimento, tendo em vista a necessidade da pecuária se tornar mais competitiva, tanto na questão zootécnica quanto do ponto de vista econômico. Segundo Valadares Filho et al. (2002) uma das grandes aplicações do conhecimento de nutrição de ruminantes no Brasil foi a implantação da suplementação a pasto.

Estratégias de suplementação que visam o fornecimento de ingredientes volumosos para bovinos em situações restritas de pastejo, têm efeito positivo em termos de manejo dos animais, uma vez que o fornecimento desses suplementos possibilita que a massa de forragem pré-pastejo seja utilizada por um maior número de animais, ou seja, a taxa de lotação da pastagem pode ser aumentada em função da indução do efeito substitutivo da suplementação (Paulino et al., 2004). Contudo, de forma geral tais estratégias de suplementação devem ser avaliadas quanto à sua duração, número de animais a serem suplementados e custos da suplementação, uma vez que se considera que o adequado manejo e disponibilização de gramíneas forrageiras em quantidade e qualidade mínimas são premissas básicas para estratégias de suplementação de bovinos a pasto.

Segundo a Instrução Normativa no 15, de 26.05.2009 do MAPA, Suplemento: é a mistura composta por ingredientes ou aditivos, podendo conter veículo ou excipiente, que deve ser fornecida diretamente aos animais ou ser indicada para diluição, para melhorar o balanço nutricional. 
TEIXEIRA, U.H.G. et al. Co-produtos agroindustriais para suplementos. PUBVET, Londrina, V. 8, N. 14, Ed. 263, Art. 1749, Julho, 2014.

A utilização de suplementação tem por objetivo atender as exigências nutricionais dos animais, complementando o valor nutritivo da forragem, a fim de se alcançar o desempenho desejado, podendo alcançar melhores índices de produção (Euclides \& Medeiros, 2005).

Lana (2002) diz que as principais vantagens de suplementar, são: suprir os nutrientes para os animais, utilizar as pastagens de modo mais adequado, evitar a subnutrição, melhorar a eficiência alimentar, auxiliar na desmama precoce, reduzir a idade do primeiro parto, reduzir o intervalo entre partos, diminuir a idade de abate, aumentar a taxa de lotação das pastagens e auxiliar na terminação de animais de descarte.

A necessidade de se suplementar os animais e as quantidades utilizadas depende do objetivo esperado no sistema, o desafio é prenunciar com eficiência o impacto que a suplementação terá no desempenho animal. Deste modo uma estratégia de suplementação eficiente será aquela destinada a maximizar o consumo e a digestibilidade da forragem disponível na pastagem (Reis et al., 1997).

Para que a prática da suplementação seja iniciada deve haver um conhecimento geral de todos os aspectos relacionados às pastagens e às exigências nutricionais dos animais. Tais exigências podem ser afetadas pela idade, tamanho do corpo do animal, taxa de crescimento, gestação e lactação, atividade muscular, relação com outros nutrientes e fatores do meio ambiente, tais como: temperatura, umidade, intensidade solar e velocidade do vento (NRC, 1981).

\section{CO-PRODUTOS}

No beneficiamento de matérias-primas vegetais para a obtenção de um produto principal, geralmente são obtidos outros materiais secundários os quais, até pouco tempo atrás, eram denominados de subprodutos (produtos com menos importância em relação ao faturamento) e resíduos (produtos sem mercado definido). 
TEIXEIRA, U.H.G. et al. Co-produtos agroindustriais para suplementos. PUBVET, Londrina, V. 8, N. 14, Ed. 263, Art. 1749, Julho, 2014.

No entanto, vários estudos têm demonstrado que estes produtos secundários podem ser usados como matéria-prima para extração e interconversão em outros produtos de maior valor agregado. Nesse sentido, atualmente o conceito de co-produto tem ganhado força, uma vez que estes produtos podem ser tão importantes industrial e comercialmente, como o produto principal objetivado no processamento (Retore, 2009).

Os co-produtos podem ser originados após a extração do óleo de sementes de oleaginosas (tortas e farelos) e após o processo de conversão de triglicerídeos em biodiesel por meio de transesterificação (glicerina bruta), os quais, em conjunto, representam mais de $50 \%$ da massa inicial de sementes utilizada na cadeia agroindustrial. Segundo Abdalla et al. 2008 o Brasil possui varias culturas oleaginosas com características e potencial para produção de biodiesel (Tabela 1) que gera co-produtos para alimentação animal como soja (Glycine max), o girassol (Helianthus annuus), a mamona (Ricinus communis), o dendê (Elaeis guineensis), o pinhão-manso (Jatropha curcas), o nabo forrageiro (Raphanus sativus), o algodão (Gossypium spp. L.), o amendoim (Arachis hypogaea), a canola (Brassica napus), o gergelim (Sesamum arientale), o babaçu (Orrbignya speciosa) e a macaúba (Acrocomia aculeata).

De acordo com Pereira et al. (2009) o Brasil também possui uma grande variedade de frutas que através do seu processamento nas agroindústrias gera grandes quantidade de co-produtos (Tabela 2) como: abacaxi (Anamas comosus), acerola (Malpighia glaba), caju (Anacardium occidentalis L.), goiaba (Psidium guajava L.), graviola (Annoma muricata), jaca (Artocarpus heterofhyllus Lamb.), laranja (Citrus sinensis), maçã (Pyrus malus), manga (Manguifera edulis F.), Maracujá (Passiflora ligularis), melão (Cucumis melo L.), pêssego (Prumus persica), pitanga (Eugenia uniflora L.), tamarindo (Tamarindus indica L.), umbu (Spondias tuberosa Arruda), uva (Vitis vinifera L.). 
TEIXEIRA, U.H.G. et al. Co-produtos agroindustriais para suplementos. PUBVET, Londrina, V. 8, N. 14, Ed. 263, Art. 1749, Julho, 2014.

Tabela 1. Teor de óleo (\%), produtividade (Kg/ha/ano) e produção de óleo ( $\mathrm{Kg} / \mathrm{ha} / \mathrm{ano})$ de algumas oleaginosas com potencial para produção de biodiesel no Brasil.

\begin{tabular}{lccc}
\hline Espécie & Teor de óleo (\%) & $\begin{array}{c}\text { Produtividade } \\
(\mathrm{kg} / \mathrm{ha} / \mathrm{ano})\end{array}$ & $\begin{array}{c}\text { Produção de óleo } \\
(\mathrm{kg} / \mathrm{ha} / \mathrm{ano})\end{array}$ \\
\hline Amendoim & 49 & 1800 & 882 \\
Babaçu & 4 & 15000 & 600 \\
Canola & 38 & 1800 & 684 \\
Caroço de algodão & 15 & 1800 & 270 \\
Dendê/Palma & 20 & 10000 & 2000 \\
Gergelim & 39 & 1000 & 390 \\
Girassol & 43 & 1600 & 672 \\
Mamona & 44 & 1500 & 660 \\
Nabo forrageiro & 29 & 500 & 145 \\
Pinhão-manso & 40 & 8000 & 3200 \\
Soja & 19 & 2200 & 418
\end{tabular}

Adaptado de: Abdalla et al.,2008. 
TEIXEIRA, U.H.G. et al. Co-produtos agroindustriais para suplementos. PUBVET, Londrina, V. 8, N. 14, Ed. 263, Art. 1749, Julho, 2014.

Tabela 2. Total de co-produtos provenientes do beneficiamento industrial e/ou processamento secundário de produtos agrícolas.

Fruta

abacaxi (Anamas comosus)

acerola (Malpighia glaba)

caju (Anacardium occidentalis L.)

goiaba (Psidium guajava L.)

graviola (Annoma muricata)

jaca (Artocarpus heterofhyllus Lamb.)

laranja (Citrus sinensis)

maçã (Pyrus malus)

manga (Manguifera edulis F.)

Maracujá (Passiflora ligularis)

melão (Cucumis melo L.)

pêssego (Prumus persica)

pitanga (Eugenia uniflora L.)

tamarindo (Tamarindus indica L.)

umbu (Spondias tuberosa Arruda)

uva (Vitis vinifera L.)
Total de co-produto

40 a $50 \%$

27 a $41 \%$

$40 \%$

13 a $20 \%$

$35 \%$

$70 \%$

42 a $50 \%$

25 a $35 \%$

60 a $70 \%$

54 a $70 \%$

$45 \%$

25 a $30 \%$

$70 \%$

50 a $60 \%$

$45 \%$

20 a $30 \%$

Adaptado de: Pereira et al. (2009).

\section{CO-PRODUTO DO ALGODÃO (CAROÇO E FARELO)}

O caroço de algodão compreende o grão e as cascas. Nele ficam ainda as fibras curtas presas ao grão denominadas línter, cujo teor pode variar de $4 \%$ a $8 \%$ no caroço, que também servem como fonte de fibra facilmente digestível para os ruminantes, além de ser efetiva, com real capacidade de estimular o rúmen (Fernandes et al., 2002). Embora grande parte do caroço seja prensada para produção de óleo, é bastante expressivo o seu uso na alimentação de ruminantes na forma integral. 
TEIXEIRA, U.H.G. et al. Co-produtos agroindustriais para suplementos. PUBVET, Londrina, V. 8, N. 14, Ed. 263, Art. 1749, Julho, 2014.

Apresentando um fator antinutricional denominado de gossipol, o qual confere ao caroço de algodão um determinado grau de resistência às pragas e às doenças fúngicas (Carvalho, 1996).

O teor de gossipol total presente no caroço de algodão varia entre 0,59\% a 2,35\%, não sendo considerado tóxico ao ruminante em conseqüência da ligação do gossipol a proteínas solúveis no rúmen, que previne a absorção do gossipol no intestino delgado, entretanto este poderá interferir na consumo de MS total das dietas (Zeoula, 2002).

Paulino et al. (2002) relataram que o caroço de algodão pode ser fornecido como ingrediente de suplementos múltiplos concentrados (misturas múltiplas), como suplemento único ou misturado a dietas completas. Estes autores ao fornecerem suplementos múltiplos constituídos por soja grão e caroço de algodão inteiros em relação a suplemento padrão de milho mais farelo de soja para 12 novilhos mestiços Holandês-Zebu de $361 \mathrm{~kg}$ terminados a pasto de Brachiaria decumbens, durante a época seca, consumindo 4 $\mathrm{kg} /$ animal/dia de suplemento, verificaram que o emprego de grão de soja ou caroço de algodão em suplementos balanceados para $20 \%$ de PB na matéria natural propiciou desempenho animal semelhante ao obtido com o uso do farelo de soja, considerando ganho médio diário de peso, rendimento de carcaça e peso de carcaça quente.

O caroço de algodão é uma fonte de gordura muito utilizada em fazendas especializadas na produção de leite e de carne como ingrediente da dieta de bovinos, pois este apresenta valores de $82 \%$ de nutrientes digestíveis totais (NDT), 23\% de proteína bruta (PB), 44\% de fibra em detergente neutro (FDN) e $19 \%$ de extrato etéreo (Valadares Filho et al., 2006).

Zeoula et al., 2004 avaliarão a degradabilidade in situ da matéria seca e proteína bruta de três concentrados diferentes, os concentrados continham alto teor de amido (AMI) foi utilizado o milho como fonte de amido; contendo alto teor de óleo (OLE) onde utilizou-se caroço de algodão e um composto contendo amido e óleo $(A+O)$ que foi constituído pela mistura dos concentrados AMI e OLE. 
TEIXEIRA, U.H.G. et al. Co-produtos agroindustriais para suplementos. PUBVET, Londrina, V. 8, N. 14, Ed. 263, Art. 1749, Julho, 2014.

Os autores observaram (Tabela 3) maior degradabilidade potencial (DP) para o concentrado AMI seguido pelos concentrados $A+O$ e OLE. Quanto à degradabilidade efetiva ( $D E)$, o mesmo comportamento se repete. Para as três taxas de passagem $(2 \%, 5 \%$ e $8 \% / h)$, o concentrado AMI foi superior aos demais, o OLE inferior e $A+O$ intermediário. Para a proteína bruta observa-se que a DP, quando o fator tempo não é limitante, foi semelhante para todos os concentrados, porém, a $\mathrm{DE}$ da $\mathrm{PB}$, para as taxas de passagem 2 e $5 \% / \mathrm{h}$ do concentrado AMI, foi superior ao concentrado $A+O$, não diferindo do concentrado OLE, que apresentou DE da PB intermediária, não diferindo das demais. Para uma maior ingestão, isto é, para uma taxa de passagem de sólidos de $8 \% / \mathrm{h}$ a DE da proteína do concentrado AMI foi superior a OLE e $A+O$, as quais não diferiram entre si.

Tabela 3. Degradabilidade potencial (DP) e degradação efetiva (DE) da matéria seca (MS) e da proteína bruta (PB) dos concentrados para taxas de passagem de $2 \%, 5 \%$ e $8 \% / h$.

\begin{tabular}{lcccc}
\hline \multirow{2}{*}{ Concentrado } & DP da MS & \multicolumn{3}{c}{$\mathrm{DE}(\%) \mathrm{MS}$} \\
\cline { 3 - 5 } & & $2 \% / \mathrm{h}$ & $5 \% / \mathrm{h}$ & $8 \% / \mathrm{h}$ \\
\hline AMI & $94,76 \mathrm{~A}$ & $80,88 \mathrm{a}$ & $69,17 \mathrm{a}$ & $62,30 \mathrm{a}$ \\
OLE & $77,63 \mathrm{C}$ & $63,45 \mathrm{c}$ & $52,99 \mathrm{c}$ & $47,36 \mathrm{~b}$ \\
$\mathrm{~A}+\mathrm{O}$ & $84,38 \mathrm{~B}$ & $72,03 \mathrm{~b}$ & $61,15 \mathrm{~b}$ & $54,56 \mathrm{~b}$ \\
\hline & $\mathrm{DP} \mathrm{da} \mathrm{PB}$ & \multicolumn{3}{c}{$\mathrm{DE}(\%) \mathrm{PB}$} \\
\hline AMI & $94,89 \mathrm{a}$ & $86,98 \mathrm{a}$ & $79,42 \mathrm{a}$ & $74,55 \mathrm{a}$ \\
OLE & $93,31 \mathrm{a}$ & $82,83 \mathrm{ab}$ & $73,59, \mathrm{ab}$ & $67,50 \mathrm{~b}$ \\
A+O & $92,24 \mathrm{a}$ & $80,24 \mathrm{~b}$ & $69,41 \mathrm{~b}$ & $62,71 \mathrm{~b}$
\end{tabular}

AMI: Concentrado rico em amido, OLE: Concentrado rico em óleo, $\mathrm{A}+\mathrm{O}$ : Concentrado de amido+óleo. Médias seguidas por letras diferentes na mesma coluna são diferentes pelo teste Tukey $(p<0,01)$.

Adaptado de Zeoula et al. (2004).

Moraes et al. (2006) avaliaram diferentes fontes protéicas (GS - grão de soja ou CA - caroço de algodão inteiros) e energéticas (FT - farelo de trigo ou FA - farelo de arroz) em suplementos múltiplos sobre o desempenho de 20 
TEIXEIRA, U.H.G. et al. Co-produtos agroindustriais para suplementos. PUBVET, Londrina, V. 8, N. 14, Ed. 263, Art. 1749, Julho, 2014.

novilhos mestiços Holandês x Zebu na fase de recria em pastagem de Brachiaria brizantha, no período da seca, consumindo diariamente suplemento na proporção de $0,75 \%$ do peso corporal, não verificaram diferenças no ganho médio diário, no peso vivo final e no ganho de peso total. Diante disso, concluíram que a opção por uma das fontes protéicas ou energéticas estudadas depende, principalmente, do preço e da disponibilidade no mercado pelo fato de não ter verificado diferenças no desempenho dos animais que receberam suplementação.

Júnior et al. (2008) relataram que grande parte da proteína do algodão é degradada no rúmen (77\%), o que é uma característica interessante do ponto de vista nutricional, considerando a disponibilidade do nitrogênio desse alimento para síntese de proteína microbiana. Alem disso, $80 \%$ da proteína não degradada no rúmen desse alimento é aproveitada pelo animal.

Costa (2009) objetivando avaliar o efeito da inclusão de diferentes níveis (0; 14,35; 27,51 e 34,09\%) de caroço de algodão na terminação em confinamento de bovinos Nelore não castrados, sobre a composição centesimal, maciez, cor e oxidação lipídica da carne de no vilhos Nelore, verificou que o aumento nos níveis de caroço de algodão na alimentação de novilhos Nelore não modificou a concentração de ácido linoléico conjugado, dos ácidos graxos saturados e dos insaturados totais. Contudo, o aroma e sabor da carne são alterados negativamente pela inclusão de caroço de algodão acima de 14,35 e $27,51 \%$ da dieta, respectivamente.

Zanin (2009) avaliou níveis de substituição da proteína oriunda do farelo de soja pela proteína do farelo de algodão de alta energia em suplementos múltiplos (2,0 kg/animal/dia - 0,5\% PC) para novilhos da raça Nelore em pastejo no período seco do ano, sobre os ganhos de peso total (GP Total), GMD e viabilidade econômica. Na Tabela 4 tem-se a composição percentual dos suplementos com base na matéria natural. Verifica-se através dos resultados apresentados na Tabela 5 que o desempenho animal foi influenciado positivamente pelo aporte protéico ofertado aos animais via suplementação. 
TEIXEIRA, U.H.G. et al. Co-produtos agroindustriais para suplementos. PUBVET, Londrina, V. 8, N. 14, Ed. 263, Art. 1749, Julho, 2014.

Tabela 4. Composição percentual do suplemento controle (SAL) e dos suplementos com diferentes níveis de inclusão do farelo de algodão de alta energia: (OFA; 25FA; 50FA) expressa com base na matéria natural.

Suplementos

\begin{tabular}{lcccc}
\cline { 2 - 5 } Ingredientes & $\mathrm{MM}$ & $\mathrm{OFA}^{2}$ & $25 \mathrm{FA}^{3}$ & $50 \mathrm{FA}^{4}$ \\
\hline Casquinha de soja & - & 49,0 & 42,7 & 36,5 \\
Farelo de Soja & - & 42,0 & 31,5 & 21,0 \\
Farelo de Algodão de alta energia $^{\text {Uréia/Sulfato de Amônia }}{ }^{9: 1}$ & - & - & 16,5 & 33,0 \\
Sal mineral $^{1}$ & - & 4,0 & 4,3 & 4,5 \\
\end{tabular}

\footnotetext{
${ }^{1}$ Mistura mineral comercial; ${ }^{2} 0 \%$ da proteína do farelo de soja pelo farelo de algodão de alta energia; ${ }^{3} 25 \%$ da proteína do farelo de soja pelo farelo de algodão de alta energia; ${ }^{4} 50 \%$ da proteína do farelo de soja pelo farelo de algodão de alta energia.

Fonte: Adaptado de Zanin (2009).
}

Tabela 5. Peso corporal inicial, peso corporal final, valores médios para ganho de peso total e ganho médio diário em função do grupo controle (SAL) e dos níveis de inclusão do farelo de algodão de alta energia substituindo farelo de soja nos suplementos.

\section{Suplementos}

\begin{tabular}{lcccc}
\cline { 2 - 5 } Variaveis & MM & OFA & 25FA & 50FA \\
\hline Peso corporal inicial ${ }^{\mathrm{kg}}$ & 354,20 & 349,8 & 350,8 & 350,20 \\
Peso corporal final $^{\mathrm{kg}}$ & 352,60 & 394,00 & 423,80 & 400,40 \\
Ganho de peso total $^{\mathrm{kg}}$ & $-1,60$ & 44,20 & 63,00 & 50,20 \\
Ganho médio diário $^{\mathrm{kg} / \text { animal/dia }}$ & $-0,02 \mathrm{c}$ & $0,53 \mathrm{~b}$ & $0,75 \mathrm{a}$ & $0,60 \mathrm{~b}$
\end{tabular}

Valores seguidos de letras iguais na linha, não diferem entre si pelo teste SNK a $10 \%$ de significância.

Fonte: Adaptado de Zanin (2009).

Outro fator favorável a utilização de com-produtos de algodão, disrespeito ao farelo de algodão que pode ser utilizado como fonte de proteína verdadeira em suplementos múltiplos, pois proporciona desempenhos condizentes com aqueles preconizados para bovinocultura de ciclo curto em pastagem em condições de seca, esse fato tem grande importância por ocasião da decisão de quais ingredientes serão utilizados na composição dos suplementos múltiplos, 
TEIXEIRA, U.H.G. et al. Co-produtos agroindustriais para suplementos. PUBVET, Londrina, V. 8, N. 14, Ed. 263, Art. 1749, Julho, 2014.

a suplementação com farelo de algodão pode reduzir a digestibilidade total da FDN e dos carboidratos totais, possivelmente devido aos maiores níveis de componentes fibrosos desse suplemento (Machado et al., 2011).

Paula et al. (2010) avaliando desempenho econômico de freqüência de suplementação e fontes de proteína para recria de bovinos em pastejo no período seco, perceberam que o farelo de algodão, aliado à suplementação 3 vezes/semana proporcionou os melhores resultados, as variações no custo da suplementação atribuídas às fontes protéicas e à freqüência de fornecimento constituíram-se o grande diferencial na remuneração do capital investido, tornando então o farelo de algodão uma fonte viável para a suplementação.

O farelo do algodão é o coproduto resultante da extração, em duas etapas, do óleo contido no grão, que primeiramente é esmagado dando origem à chamada torta, e depois submetida à extração com solventes, moagem e peletização. Em função do tipo da extração, podem-se produzir dois tipos de produtos: a torta gorda ( $5 \%$ de óleo residual) mais energética, proveniente apenas da prensagem mecânica, porém com menor teor de proteína; torta magra (menos de $2 \%$ de óleo residual) oriunda da extração por solventes, que apresenta concentração relativamente maior de proteína.

No Brasil são comercializados dois diferentes tipos de farelos com teores de proteína bruta de 28 ou $38 \%$, porém ambos possuem níveis nutricionais inferiores aos encontrados no farelo de soja especialmente no que se refere ao farelo de algodão com $28 \%$ de PB. Isto provavelmente se deve a incorporação de maior proporção de cascas do caroço aos farelos de algodão. A utilização do farelo de algodão de alta energia em suplementos múltiplos em substituição ao farelo de soja é satisfatória, principalmente do ponto de vista econômico.

\section{CASCA DE SOJA}

A substituição de grãos de cereais, em especial o milho, por outras fontes de energia na alimentação de ruminantes torna-se de grande importância uma vez que se possa baratear o custo de produção animal e evitando utilização de alimentos usada na alimentação humana. Entre as possibilidades, a casca de 
TEIXEIRA, U.H.G. et al. Co-produtos agroindustriais para suplementos. PUBVET, Londrina, V. 8, N. 14, Ed. 263, Art. 1749, Julho, 2014.

soja (CS) constitui alternativa interessante para substituir, em parte, o milho em grão em dietas para ruminantes, esse co-produto é composto principalmente de fibras, que tem pouco valor na alimentação humana e no uso industrial. No entanto, suas características físico-químicas, a facilidade de aquisição em algumas regiões e seu preço competitivo torna a CS um ingrediente atrativo para uso em rações para ruminantes (Pedroso et al., 2007).

Ao avaliarem o desempenho de ovinos com níveis crescente $(0,4,8,12$ e 16\%) da casca proteinada de soja Peripolli et al. (2011) perceberam que o níveis de inclusão não afetaram o ganho médio diário e a conversão alimentar dos animais (Tabela 6), segundo os autores a casca proteinada de soja é ingrediente alternativo ao farelo de soja, pois não altera o consumo de matéria seca, ganho de peso e conversão alimentar dos animais.

Tabela 6. Desempenho de ovinos alimentados com níveis crescentes de casca proteinada de soja na dieta.

\begin{tabular}{lccccccc}
\hline \multirow{2}{*}{ Variável } & \multicolumn{8}{c}{ Nível de casca proteinada de soja (\%) } & \multirow{2}{*}{ Média } & \multirow{2}{*}{ CV (\%) } \\
\cline { 2 - 7 } & 0 & 4 & 8 & 12 & 16 & & \\
\hline Consumo de MS $\left(\mathrm{g} \mathrm{dia}^{-1}\right.$ ) & 0,93 & 0,82 & 0,82 & 0,83 & 0,89 & 0,85 & 10,74 \\
Ganho de peso $\left(\mathrm{kg}^{2}\right)$ & 9,37 & 8,31 & 7,57 & 5,85 & 6,22 & 7,46 & 20,10 \\
Ganho médio $\left(\mathrm{g} \mathrm{dia}^{-1}\right)$ & 0,16 & 0,15 & 0,13 & 0,10 & 0,11 & 0,13 & 20,07 \\
Conversão alimentar & 7,99 & 7,92 & 9,32 & 11,19 & 11,22 & 9,53 & 26,31
\end{tabular}

CV: coeficiente de variação. Fonte: Peripolli et al. (2011).

Paris et al. (2005) trabalharam com suplementação de bovinos em pastagem de Coastcross no período das águas, foram utilizados duas fontes de energia para formulação do suplemento que foi a casca de soja (CS) e o grão de aveia ( $\mathrm{AV}$ ), foi feito quatro tratamentos. Ao avaliarem o ganho médio diário (GMD) dos animais (Tabela 7) viram que as fontes de energia utilizadas na formulação dos suplementos não influenciaram no desempenho dos animais, já o ganho de peso vivo por há-1 foi diminuindo com o avanço dos períodos experimental, os autores concluíram que o desempenho animal em pastagem de Coastcross durante o período das águas está diretamente relacionado com 
TEIXEIRA, U.H.G. et al. Co-produtos agroindustriais para suplementos. PUBVET, Londrina, V. 8, N. 14, Ed. 263, Art. 1749, Julho, 2014.

a massa de forragem, assim como com a massa de lâminas foliares, já que a suplementação com grãos de aveia preta ou casca de soja, não refletiu melhoria no ganho médio diário e ganho de peso vivo por hectare.

Tabela 7. Ganho de peso vivo médio diário (GMD) e ganho de peso vivo por área (GPV/ha) dos animais que receberam suplementos energéticos em pastagem de Coastcross durante o período das águas.

\begin{tabular}{lcccccc} 
& \multicolumn{9}{c}{ Tratamentos } & & CV (\%) \\
\cline { 2 - 5 } & SS & CS & AV & CSAV & Média & \\
\hline GMD (kg) & 0,667 & 0,840 & 0,838 & 0,833 & 0,795 & 14,60 \\
GMD P1 & 0,838 & 1,005 & 1,042 & 1,185 & 1,017 a & \\
GMD P2 & 0,804 & 1,103 & 0,875 & 0,777 & $0,890 \mathrm{a}$ & \\
GMD P3 & 0,746 & 0,681 & 0,879 & 0,815 & $0,780 \mathrm{a}$ & \\
GMD P4 & 0,282 & 0,574 & 0,556 & 0,556 & $0,492 \mathrm{~b}$ & \\
\hline GPV/ha (kg) & 159,1 & 207,8 & 214,8 & 212,0 & 198,4 & 14,33 \\
GPV/ha P1 & 187,7 & 225,1 & 233,4 & 265,4 & $227,9 \mathrm{a}$ & \\
GPV/ha P2 & 180,1 & 278,0 & 220,5 & 195,8 & $218,6 \mathrm{a}$ & \\
GPV/ha P3 & 192,5 & 188,6 & 254,9 & 236,4 & $218,1 \mathrm{a}$ & \\
GPV/ha P4 & 76,1 & 139,5 & 150,1 & 150,1 & $129,0 \mathrm{~b}$ & \\
\hline
\end{tabular}

(Períodos: 1- 24/11 a 21/12; 2- 21/12 a 18/01; 3-18/01 a 16/02; 4- 16/02 a 15/03); SS: sem suplementação; CS: casca de soja à 0,6\%PV; AV: aveia preta $0,6 \% \mathrm{PV}$; AVCS: aveia + casca de soja à $0,6 \% \mathrm{PV}$. Médias com letras diferentes na mesma linha ou coluna apresentam diferenças significativas pelo teste Tukey $(P<0,05)$. Fonte: Paris et al. 2005.

\section{TORTA DE GIRASSOL}

A torta de girassol é o resultado do processo de prensagem a frio dos grãos de girassol, por meio de prensas mecânicas (Figura 1). O outro produto resultante é o óleo de girassol bruto ou virgem. A torta é obtida apenas por meio da prensagem a frio. O farelo, pela prensagem e pelo uso de calor e de solventes químicos. Dessa forma, a torta contém certa quantidade de óleo, ao passo que o farelo possui apenas de 0,5 a $5 \%$ de óleo. A composição bromatológica da torta pode variar, dependendo do tipo de prensa, bem como 
TEIXEIRA, U.H.G. et al. Co-produtos agroindustriais para suplementos. PUBVET, Londrina, V. 8, N. 14, Ed. 263, Art. 1749, Julho, 2014.

da sua regulagem. Por exemplo, prensas que extraem mais óleo dão tortas com menos gordura, mas com teor maior de proteína (Oliveira et al., 2003).

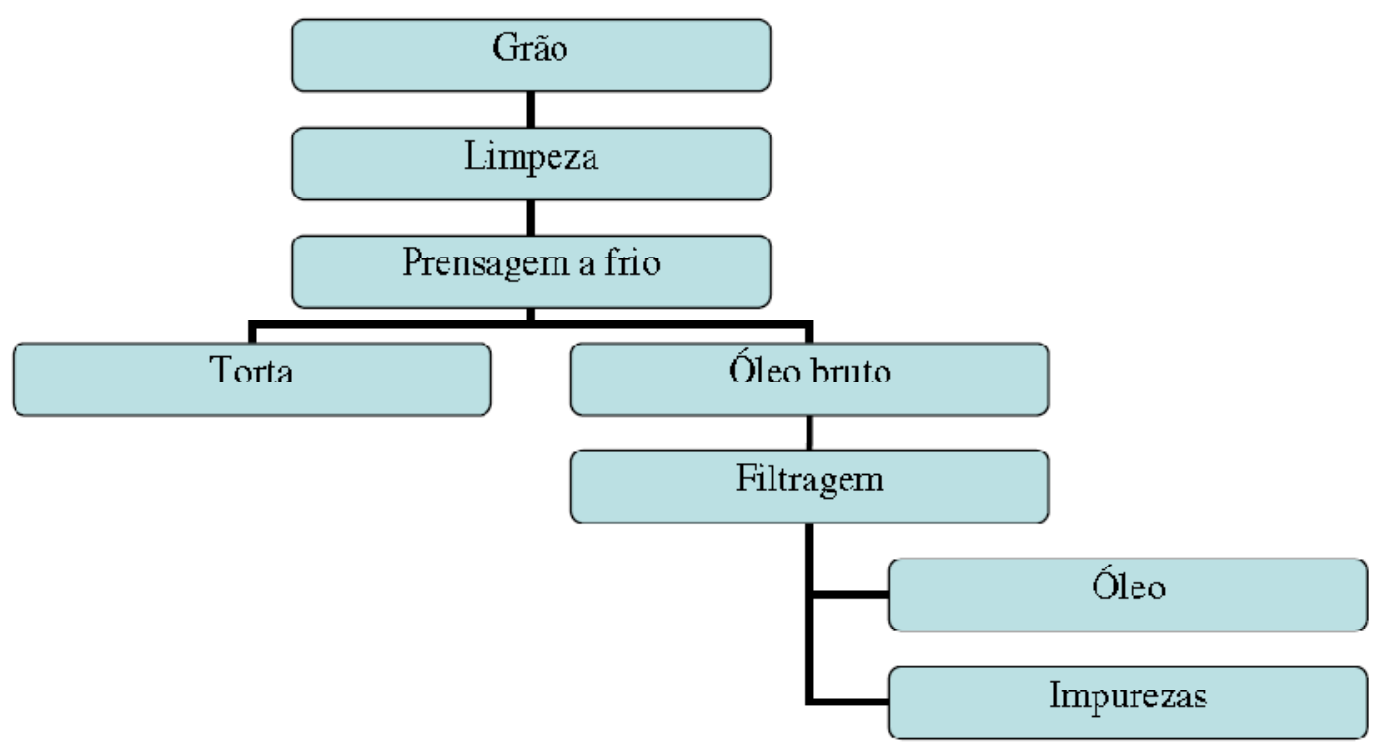

Figura 1. Fluxograma de extração da torta de girassol em pequena escala, e em prensagem a frio utilizando-se semi prensa. Adaptado de Oliveira et al. (2003).

Segundo Leite et al. (2007), em média, para cada tonelada de grão, são produzidos $400 \mathrm{~kg}$ de óleo, $250 \mathrm{~kg}$ de casca e $350 \mathrm{~kg}$ de torta, com 45 a 50\% de proteína bruta (dependendo do processo de extração) sendo este coproduto, basicamente, aproveitado na produção de ração, em misturas com outras fontes de proteína. O valor nutricional da torta de girassol é dependente do seu processo de extração, podendo o mesmo apresentar valores de proteína bruta inferiores, porém elevados teores de extrato etéreo.

Oliveira (2010) avaliando a produção de leite (PL) de 16 vacas em lactação mestiças holandês/zebu relata que a inclusão da TG provocou redução linear na produção de leite. Entretanto, deve ter havido aumento na proporção de gordura, pois se admitindo a correção para 3,5\% não foi observada diferença significativa na produção de leite com a inclusão de até $72 \%$ da TG (Tabela 8). 
TEIXEIRA, U.H.G. et al. Co-produtos agroindustriais para suplementos. PUBVET, Londrina, V. 8, N. 14, Ed. 263, Art. 1749, Julho, 2014.

Tabela 8 . Produção de leite $(\mathrm{Kg} / \mathrm{dia})$ e produção de leite corrigida para $3,5 \%$ de gordura $(\mathrm{Kg} / \mathrm{dia})$ de vacas recebendo torta de girassol em diferentes níveis de inclusão na ração concentrada.

\begin{tabular}{|c|c|c|c|c|c|c|c|c|c|}
\hline \multirow{2}{*}{\multicolumn{2}{|c|}{ Variável }} & \multicolumn{4}{|c|}{ Tratamentos $^{1}$} & \multirow{2}{*}{ Média } & \multirow{2}{*}{$\mathrm{CV}^{2}$} & \multicolumn{2}{|l|}{$P^{3}$} \\
\hline & & TO & T24 & T48 & T72 & & & $\mathrm{L}$ & $\mathrm{Q}$ \\
\hline PL (kg/dia) & & $17,4^{\mathrm{a}}$ & $17,6^{a}$ & $16,2^{\mathrm{ab}}$ & $14,8^{b}$ & 16,5 & 5,4 & $<0,0001^{* *}$ & ns \\
\hline $\begin{array}{l}\text { LCG } \\
\text { (kg/dia) }\end{array}$ & $3,5 \%$ & $17,5^{\mathrm{a}}$ & $17,3^{a}$ & $16,5^{\mathrm{a}}$ & $16,0^{a}$ & 16,8 & 5,6 & Ns & ns \\
\hline
\end{tabular}

Médias seguidas de letras diferentes na linha diferem entre si pelo teste de Tukey $(\mathrm{P}<0,05)$. PL=produção de leite; $\mathrm{LCG} 3,5 \%=$ Produção de leite corrigida para 3,5\% de gordura. ${ }^{1} \mathrm{~T} 0=$ Tratamento controle; T24, T48 e T72, inclusão de 24, 48 e 72 da TG na MS dos concentrados. ${ }^{2} \mathrm{CV}=$ coeficiente de variação. ${ }_{3} \mathrm{P}=$ probabilidade dos contrastes ortogonais (linear e quadrático). Fonte: Oliveira (2010).

Porem Cerilo (2010), trabalhando com torta de girassol em substituição ao farelo de soja em suplementos para novilhas nelores terminadas a pasto durante a estação seca mostra (Tabela 9) que a utilização de concentrados contendo torta de girassol aumentou o ganho médio diário das novilhas em pastejo. A condição corporal (CC) dos animais também melhorou com a substituição do farelo de soja pela torta de girassol, onde os animais suplementados com torta de girassol apresentaram a melhor CC final $(4,0,4,0$ e 3,7 ) para os níveis de substituição de 20 , 40e $60 \%$, respectivamente. Os animais suplementados com milho e soja apresentaram CC final 3,6.

\section{CONCLUSÕES}

Existem diversos co-bprodutos da indústria do biodiesel com potencial muito significativo e rentável para serem utilizados em suplementos para bovinos. Desde que haja disponibilidade na região e conhecimento desses subprodutos eles podem beneficiar as indústrias, que visam dar destino a esses produtos sem causar impacto ambiental, e produtores que buscam alternativas para diminuir o custo de produção. 
TEIXEIRA, U.H.G. et al. Co-produtos agroindustriais para suplementos. PUBVET, Londrina, V. 8, N. 14, Ed. 263, Art. 1749, Julho, 2014.

Tabela 9. Valores médios para peso vivo inicial (PVI) e final (PVF), ganho de peso diário (GDP), condição corporal inicial (CCI), condição corporal final (CCF), consumo de matéria seca do suplemento (CSUPL), forragem (CMSF) e total (CMST) dos animais.

\begin{tabular}{|c|c|c|c|c|c|c|}
\hline \multirow[b]{2}{*}{ Item } & \multicolumn{4}{|c|}{ Substituição de farelo de soja } & \multirow{2}{*}{ Média } & \multirow{2}{*}{$\mathrm{CV}(\%)$} \\
\hline & 00 & 20 & 40 & 60 & & \\
\hline PVI $(k g)^{\mathrm{ns}}$ & 318,6 & 313,8 & 305,2 & 308 & $311,4 \pm 23,35$ & 7,9 \\
\hline $\operatorname{PVF}(\mathrm{kg})^{\mathrm{ns}}$ & 344 & 357 & 351,4 & 341,4 & $348,5 \pm 30,07$ & 9,2 \\
\hline GPD (kg/dia)*** & $0,242^{b}$ & $0,411^{\mathrm{a}}$ & $0,440^{\mathrm{a}}$ & $0,320^{\mathrm{a}}$ & $0,350 \pm 0,14$ & 36,4 \\
\hline $\mathrm{CCI}^{\mathrm{ns}}$ & 2,1 & 2,2 & 2,5 & 2,2 & $2,3 \pm 0,34$ & 14,9 \\
\hline CCF** & $3,6^{\mathrm{b}}$ & $4,0^{\mathrm{a}}$ & $4,4^{a}$ & $3,7^{\mathrm{ab}}$ & $3,8 \pm 0,29$ & 6,5 \\
\hline CSUPL (kg/dia) & 2,65 & 2,68 & 2,63 & 2,60 & - & - \\
\hline CMSF $(\mathrm{kgMS} / \mathrm{dia})^{\mathrm{ns}}$ & 8,30 & 10,90 & 9,47 & 3,07 & $7,9 \pm 28,9$ & 44,6 \\
\hline CMST $(k g M S / d i a)^{n s}$ & 10,9 & 13,6 & 12,1 & 5,7 & $10,5 \pm 28,9$ & 68,3 \\
\hline CMST (\%PV) & 3,3 & 4,0 & 3,6 & 1,75 & - & - \\
\hline
\end{tabular}

*** Médias seguidas pelas mesmas letras não diferem entre si pelo teste de Tukey a $10 \%$ de probabilidade.

** Médias seguidas pelas mesmas letras não diferem entre si pelo teste de Tukey a $5 \%$ de probabilidade.

ns=não significativo $(P>0,10)$. Fonte: Cerilo (2010).

\section{REFERÊNCIAS}

ABDALLA, A. L. et al. Utilização de subprodutos da indústria de biodiesel na alimentação de ruminantes. Revista Brasileira de Zootecnia, Viçosa, v.37, p.260-258, 2008.

AFONSO NETO, M.J.A. Restos de cultura de resíduos agroindustriais: um aproveitamento racional. Informe Agropecuário. Belo Horizonte, ano 10, n.119, p.1-2, 1984.

CARVALHO, P.P. Manual do algodoeiro. Lisboa: Instituto de Investigação Cientifica Tropical, 1996. 282p.

CERILO, S. L. N., Torta de girassol em suplementos para novilhas nelore terminadas a pasto durante a estação seca. 2010. 62 p. Dissertação (Mestrado em Zootecnia), Programa de Pós-Graduação em Zootecnia, Faculdade de Ciências Agrárias, Universidade Federal da Grande Dourados, Dourados, 2010.

COSTA, D.P.B. Características da carne de novilhos nelore alimentados com caroço de algodão. (Tese Doutorado) Programa de Pós-Graduação em Zootecnia - UNESP Botucatu. Botucatu - SP. 59p. 2009. 
EUCLIDES, V.P.B.; MEDEIROS, S.R. de. Suplementação animal em pastagens e seu impacto na utilização da pastagem. In: SIMPÓSIO SOBRE MANEJO DA PASTAGEM, 22, 2005, Piracicaba. Anais... Piracicaba: Fealq, 2005. p.33-70.

FERNANDES, J.J.R. et al. Teores de caroço de algodão em dietas contendo silagem de milho para vacas em lactação. Acta Scientiarum, Maringá, v.24, n.4, p.1071-1077, 2002.

GALATI, R.L. ALIMENTOS DA AGROINDÚSTRIA: POTENCIALIDADES E ESTRATÉgIAS FUTURAS DE USO NA ALIMENTAÇÃO ANIMAL. In: NUTRIÇÃO E PRODUÇÃO DE BOVINOS DE CORTE. Livro. Eds.: Zervoudakis, J.T. e Cabral, L .S. Editora Gráfica Atalaia. Cuiabá-MT. p.91-126. 2011.

IBGE: Instituto Brasileiro de Geografia e Estatística. Estimativa da produção agrícola 2008. www.ibge.gov.br/ consultado em 25 de abril de 2011.

JÚNIOR, R.G.; MARTINS, C.F.; PEREIRA, L.G.R. et al. Subprodutos da agroindústria na alimentação de bovinos: caroço de algodão. In: EMBRAPA CERRADOS (Planaltina-DF). Documentos 234, p.33, 2008.

LANA, R.P. Sistema de Suplementação Alimentar para Bovinos de Corte em Pastejo. Simulação. Revista. Brasileira de Zootecnia, Viçosa, v.31, n.1, p.223-231, 2002.

LEITE, R.M.V.B., et al. Indicações para o cultivo de girassol nos Estados do Rio Grande do Sul, Paraná, Mato Grosso do Sul, Mato Grosso, Goiás e Roraima. Comunicado Técnico n.78, Londrina: Embrapa Soja. 2007. 4 P.

MACHADO, P.A.S. et al. Parâmetros nutricionais e produtivos em bovinos de corte a pasto alimentados com diferentes quantidades de suplemento. Revista Brasileira de Zootecnia, Viçosa, v.40, n.6, p.1303-1312, 2011.

MAPA- MINISTÉRIO DA AGRICULTURA, PECUÁRIA E ABASTECIMENTO. INSTRUÇÃO NORMATIVA MAPA No 15 DE 26/05/2009 (Federal).

MORAES, E.H.B.K.; PAULINO, M.F.; ZERVOUDAKIS, J.T. et al. Associação de diferentes fontes energéticas e protéicas em suplementos múltiplos na recria de novilhos mestiços sob pastejo no período da seca. Revista Brasileira de Zootecnia, v.35, n.3, p.914-920, 2006.

NATIONAL RESEARCH COUNCIL (NRC). Nutrient requeriments of domestic animals; nutrient requeriments of goats. Washington, p.91, 1981.

OLIVEIRA, A.A., Parâmetros comportamentais e fisiológicos de vacas em lactação suplementadas com torta de girassol. 2010. 60 p. Dissertação (Mestrado em Ciência Animal), Programa de Pós-Graduação em Ciência Animal,Instituto Agronômico do Paraná, Universidade Estadual de Londrina, Londrina, 2010.

OLIVEIRA, M.V.M.,et al. Degradabilidade ruminal e digestibilidade intestinal de alimentos por intermédio da técnica in situ associada à do saco de náilon móvel. Revista Brasileira de Zootecnia,Viçosa, v.32, n.6, p.2023-2031, 2003.

PAIXÃO, M.L. et al. Fontes de proteína para novilhos em pastejo no período das águas. In: Reunião Anualda Sociedade Brasileirade Zootecnia, 43, João Pessoa, 2006. Anais..., João Pessoa: SBZ, 2006. 
PARIS, W., et al. Suplementação energética de bovinos em pastagem de Coastcross (Cynodon dactylon (L.) Pers) no período das águas. Acta Scientiarum. Animal Sciences, Maringá, v.27, n.1, p.109-115, 2005.

PAULA, N.F. et al. Freqüência de suplementação e fontes de proteína para recria de bovinos em pastejo no período seco: desempenho produtivo e econômico. Revista Brasileira de Zootecnia, Viçosa, v.39, n.4, p.873-882, 2010.

PAULINO, M.F.; DETMANN, E.; VALADARES FILHO, S.C.; LANA, R.P. Soja Grão e Caroço de Algodão em Suplementos Múltiplos para Terminação de Bovinos Mestiços em Pastejo. Revista Brasileira de Zootecnia, v.31, n.1, p.484-491, 2002 (suplemento).

PAULino, M. F.; FIGUEIREDO, D. M.; MORAES, E. H. T. B.; PORTO, M.O.; ACEDO, T. S.; VILLELA, S. D. J.; VALADARES FILHO, S. C. Suplementação de bovinos em pastagens: uma visão sistêmica. In: SIMPÓSIO DE PRODUÇÃO DE GADO DE CORTE, 4, 2004, Viçosa. Anais... Viçosa: SIMCORTE, 2004, p.93-139.

PEDROSO A.M. et al. Substituição do milho moído por casca de soja na ração de vacas leiteiras em confinamento. Revista Brasileira de Zootecnia, Viçosa, v.36, n.5, p.1651-1657, 2007.

PEREIRA, J.C. et al. Degradabilidade ruminal de alguns subprodutos agroindustriais. Revista Brasileira de Zootecnia Viçosa, v.29, n.6, p.2359-2366, 2000.

PEREIRA, L.G. R. et al., Aproveitamento dos Co-produtos da Agroindústria Processadora de Suco e Polpa de Frutas para Alimentação de Ruminantes. Documento 220 EMBRAPA. Petrolina, PE, 2009.

PERIPOLLI. et al. Avaliação da casca proteinada de soja em dietas para ovinos. Acta Scientiarum. Animal Sciences, Maringá, v. 33, n. 2, p. 157-162, 2011.

REIS, R.A; et al. Suplementação da dieta de bovinos de corte como estratégia do manejo das pastagens. Revista Brasileira de zootecnia, v.38, p.147-159, 2009.

REIS, R.A., RODRIGUES, L.R.A., PEREIRA, J.R.A. Suplementação como estratégia de manejo de pastagem. In: Simpósio sobre manejo de pastagem, 13, p.123-150, Anais... Piracicaba, 1997.

RETORE, M. Caracterização da fibra de co-produtos agroindustriais e sua avaliação nutricional para coelhos em crescimento. 2009. 69 p. Dissertação (Mestrado em Zootecnia) Universidade Federal de Santa Maria, Centro de Ciências Rurais, Programa de PósGraduação em Zootecnia, Santa Maria, 2009.

ROGÉRIO, M.C.P.; et al. Resíduos de frutas na alimentação de gado de leite. In: GONÇALVES, L. C; BORGES, I.; FERREIRA, P. S. D.; Alimentos para gado de leite. - Belo Horizonte: FEPMVZ, 2009 p. 88-115.

SOUZA, O.; SANTOS. Aproveitamento de Resíduos e subprodutos agropecuários pelos ruminantes. 2002. http://www.veterinariainfoco.com.br/residuos.html. consultado em 25 de abril de 2005.

VALADARES FILHO, S.C.; et al. Modelos nutricionais alternativos para otimização de renda na produção de bovinos de corte. In: SIMPÓSIO DE PRODUÇÃO DE GADO DE CORTE, 3, Viçosa, MG. Anais... p. 197- 254, 2002. 
VALADARES FILHO, S.C.; et al. Tabelas brasileiras de composição de alimentos para bovinos. 2.ed. Viçosa: UFV, 2006, 329p.

VALADARES FILHO, S.C.; PINA, D.S. 2006. Fermentação Ruminal. In: BERCHIELLI, T.T.; PIRES, A.V.; OLIVEIRA, S.G. NUTRIÇÃO DE RUMINANTES. Jaboticabal: Funep, 583p.

ZANIN, R. Níveis de farelo de algodão de alta energia em Suplementos múltiplos para bovinos em pastejo No período seco do ano. Dissertação (Mestrado em Ciência Animal) Programa de Pós Graduação em Ciência Animal - Universidade Federal de Mato Grosso. 2009. 64p.

ZEOULA, L.M. et al. Degradabilidade in situ da matéria seca e proteína bruta de concentrados com diferentes fontes energéticas. Acta Scientiarum. Animal Sciences. Maringá, v. 26, n.2, p. 281-287, 2004.

ZEOULA, L.M. Alimentos usados na alimentação animal. In: CURSO DE ATUALIZAÇÃO POR TUTORIA À DISTÂNCIA - ATUALIZAÇÃO DA PRODUÇÃO DE BOVINOS DE CORTE, 2002, Maringá - PR. Anais... Maringá: FADEC, 2002. CD-ROM.

ZERVOUDAKIS, J.T.; SILVA, L.C.R.P.; SILVA, R.P.; JOSE NETO, A.; KOSCHECK, J.F.; SILVA, R.G.F. Otimização Do Desempenho De Bovinos Por Meio Da Suplementação À Pasto. In: I Simpósio Matogrossense De Bovinocultura De Corte - I SIMBOV MT. Eds: Zervoudakis, J.T.; José Neto, A.; Silva, R.P.; Silva, L.C.R.P.; Silva, R.G.F.; Koscheck, J.F. Cuiabá-MT.p.151194. 2011. 